\title{
CINÉTICA DE SECAGEM EM CAMADA FINA DA BANANA VERDE (Musa spp.)
}

\author{
J. D. $\operatorname{COSTA}^{1}$, A.S.SILVA ${ }^{2}$ e G.M.V. MARTINS ${ }^{3}$ \\ ${ }^{1,2,3}$ Universidade Federal de Campina Grande, Campus de Pombal, Unidade A cadêmica de \\ A gronomia e Tecnologia de Alimentos. \\ E-mail para contato: georgiana.82@gmail.com.br
}

\begin{abstract}
RESUMO - A banana (Musa spp.) fornecer quantidades significativas de vitaminas $A$ e $B$, potássio e outros minerais. Existe muito interesse na criação de novos produtos a partir da banana com o objetivo de minimizar os desperdicios podendo enriquecer ao mesmo tempo outros alimentos. O objetivo foi de estudar a cinética de secagem da banana verde (Musa spp.) para obtenção de um extrato seco que possa vir a ser utilizado como suplemento alimentar, em estufa de circulação de ar, utilizandose de planejamento experimental fatorial. A temperatura $\left(50\right.$ a $\left.70^{\circ} \mathrm{C}\right)$ e a espessura $(2$ a $4 \mathrm{~mm}$ ) são as variáveis do processo. Os modelos avaliados foram os da aproximação da difusão e Midilli. Como critério de avaliação destes utilizou-se o coeficiente de determinação e o desvio quadrático médio. Mediante os resultados obtidos observou-se que o aumento da temperatura diminuiu o tempo de secagem da banana verde. Dentre os modelos aplicados o de Midilli apresentou os maiores valores de coeficiente de determinação $\left(R^{2}\right)$ e os menores valores de DQM para a faixa de temperatura estudada.
\end{abstract}

\section{INTRODUÇÃO}

A banana (Musa spp.) é um dos frutos mais cultivados em todo o mundo. Segundo a Food and A griculture Organization of the United Nations (FAO), o Brasil no ano de 2013 estava na $5^{a}$ posição no ranking dos maiores produtores mundiais de banana depois da Índia, China, Filipinas e Equador. $O$ cultivo é realizado em todas as regiões do País, sendo que nesse ano a região que apresentou maior taxa de produção é o Nordeste, com 2. 748.646 toneladas e a cidade que apresentou a maior taxa de produção foi o Ceará com 440,810 toneladas e em segundo lugar ficando a Paraíba com 175.721 toneladas (IBGE, 2014). 
Por apresentar um amadurecimento muito rápido, a banana apresenta uma quantidade de perdas pós-colheita muito elevada. Há dados que demonstram que até $40 \%$ da produção é perdida do período da colheita até a chegada do produto à mesa do consumidor (CAMPOS, VALENTE, PEREIRA, 2003).

Deste modo, é necessária a descoberta de alternativas que diminuam essas perdas. Uma alternativa que vem sendo estudada é a desidratação. $O$ método mais comum é a secagem por convecção forçada (PONTES, 2009). A obtenção da cinética de secagem é de fundamental importância para a modelagem matemática da operação e para elaboração do projeto de secadores. É através deste estudo que se estabelecem as equações da umidade em função do tempo de secagem para os diferentes periodos e taxas de secagem. O estudo e a modelagem matemática tem despertado o interesse de vários pesquisadores para os mais diversos produtos Sousa et al.(2011).

O objetivo desse trabalho é desidratar banana verde prata (Musa ssp.) em rodelas com espessuras diferentes para estudar o processo de secagem, em estufa com circulação de ar, nas temperaturas de 50, 60 e $70{ }^{\circ} \mathrm{C}$ e estudar o ajuste de modelos matemáticos de secagem aos dados experimentais.

\section{MATERIAL E MÉTODOS}

O presente trabalho foi realizado no Laboratório de Tecnologia de Produtos Hortícolas TPH e Laboratório de Análise de Alimentos do Centro de Ciências e Tecnologia de AlimentosCCTA da Universidade Federal de Campina Grande-UFCG, Campus Pombal /PB.

Como matéria prima utilizou-se a banana verde cultivar Prata, proveniente do mercado público da cidade de Pombal-PB. As pencas de bananas foram selecionada em tamanho uniforme e no estado de maturação I de acordo com Li et al.(1997). As bananas foram lavadas, sanitizadas, descascadas e fatiadas em rodelas, com facas de aço inox, nas espessuras de 2; 3; e 4 $\mathrm{mm}$. Logo em seguida as amostras, depois de identificadas, foram dispostas em bandejas metálicas e encaminhadas para a estufa de circulação de ar. A secagem das amostras foi realizada em uma estufa de circulação de ar, nas temperaturas de 50, 60 e $70^{\circ} \mathrm{C}$, seguindo um planejamento de experimento.

A Tabela 1 apresenta a matriz de planejamento fatorial $2^{2}$, totalizando em 7 experimentos, dentre os quais 4 ensaios distintos e mais 3 no ponto central, que são 3 ensaios idênticos com uma das finalidades de verificar a reprodução dos ensaios (verificação dos erros). 
Tabela 1 - Matriz do Planejamento completo $2^{2}+3$ para secagem convectiva da banana prata verde

\begin{tabular}{ccccc}
\hline Ensaios & $\begin{array}{c}\text { Temperatura } \\
\text { (codificada) }\end{array}$ & $\begin{array}{c}\text { Espessura } \\
\text { (codificado) }\end{array}$ & $\begin{array}{c}\text { Temperatura } \\
\left(\text { real, }{ }^{\circ} \mathrm{C}\right)\end{array}$ & $\begin{array}{c}\text { Espessura } \\
(\text { real, } \mathrm{mm} \text { ) }\end{array}$ \\
\hline 1 & -1 & -1 & 50 & 2 \\
2 & +1 & -1 & 70 & 2 \\
3 & -1 & +1 & 50 & 4 \\
4 & +1 & +1 & 70 & 4 \\
5 & 0 & 0 & 60 & 3 \\
6 & 0 & 0 & 60 & 3 \\
\hline 7 & 0 & 0 & 60 & \\
\hline
\end{tabular}

$O$ teor de água inicial foi determinado pelo método padrão da estufa a $105 \pm 3{ }^{\circ} \mathrm{C}$, utilizando três sub-amostras de $10 \mathrm{~g}$ da banana verde acondicionados em recipientes de vidro, onde permaneceram durante $24 \mathrm{~h}$. A pós esse periodo, foram retirados da estufa, resfriados em dessecador durante 15 minutos e pesados em balança analítica com precisão de 0,0001.

O teor de água inicial do produto foi determinado pelo método gravimétrico, utilizando-se estufa a $105 \pm 3{ }^{\circ} \mathrm{C}$, durante $24 \mathrm{~h}$, até peso constante, em três repetições de acordo com (INSTITUTO ADOLFO LUTZ, 1985).

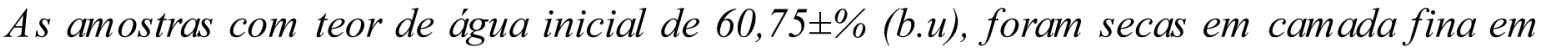
uma estufa com circulação forçada de ar, ajustado para operar nas temperaturas de 50, 60 e 70 ${ }^{\circ} \mathrm{C}$. $\mathrm{O}$ experimento foi realizado em triplicata, sendo as pesagens das rodelas de banana verde realizadas em balança semi-analitica até obtenção do equilíbrio.

O teor de água de equilibrio foi determinado através de pesagens consecutivas realizadas seguindo intervalos de tempo, iniciando-se a cada 10 minutos até que as amostras atingissem o equilíbrio. Após a obtenção das massas, calculou-se o teor de água em base úmida, em base seca e a razão de teor água para as amostras em cada temperatura e intervalo de tempo.

As curvas de secagem foram obtidas pela conversão dos dados referentes à perda de água no parâmetro adimensional razão de teor de água $(R X)$. Para determinação da razão de teor de água da banana verde para as diferentes condições de secagem foi utilizada a seguinte equação 1 :

$$
R X=\frac{x-x_{e}}{x_{o}-x_{e}}
$$


em que: $R X$ - razão de umidade ou umidade adimensional ; X - umidade absoluta, bu ; Xo umidade inicial, bu e Xe - umidade de equilíbrio, bu.

A análise e a representação dos dados experimentais do processo de secagem foram realizadas utilizando-se os modelos da aproximação da difusão e Midilli. Os parâmetros dos modelos utilizados foram obtidos mediante aplicação dos dados experimentais ao pacote de análise utilizando-se a análise de regressão não linear, pelo método Quasi-Newton, empregandose o programa computacional Statistica $5.0 \AA$.

Os critérios usados para determinação do melhor ajuste dos modelos aos dados experimentais foram: coeficiente de determinação $\left(R^{2}\right)$ e desvio quadrático médio (DQM).

As Equações 2 e 3 estão representados os modelos matemáticos para secagem em camada fina:

A proximação da difusão

$$
R U=a \exp (-k t)+(1-a) \exp (-k b t) t
$$

Midilli

$$
R U=a \exp \left(-k t^{n}\right)+b t
$$

Onde,

$R U$ - razão de teor de água; $a, b, n$ - coeficiente dos modelos; $k, k_{0}, k_{1}$, constantes de secagem (min- 1); tempo (min)

Como critério de seleção do modelo que melhor representa o processo de secagem da banana maçã, utilizou-se o coeficiente de determinação $\left(R^{2}\right)$ e o desvio quadrático médio (DQM) (Ertekin \& Yaldiz, 2004), em que quanto menor o valor de DQM melhor é a representação do modelo. 


\section{RESULTADOS E DISCUSSÃO}

A presentam-se, na Figura 1, as curvas de secagem para os experimentos realizados da matriz experimental.

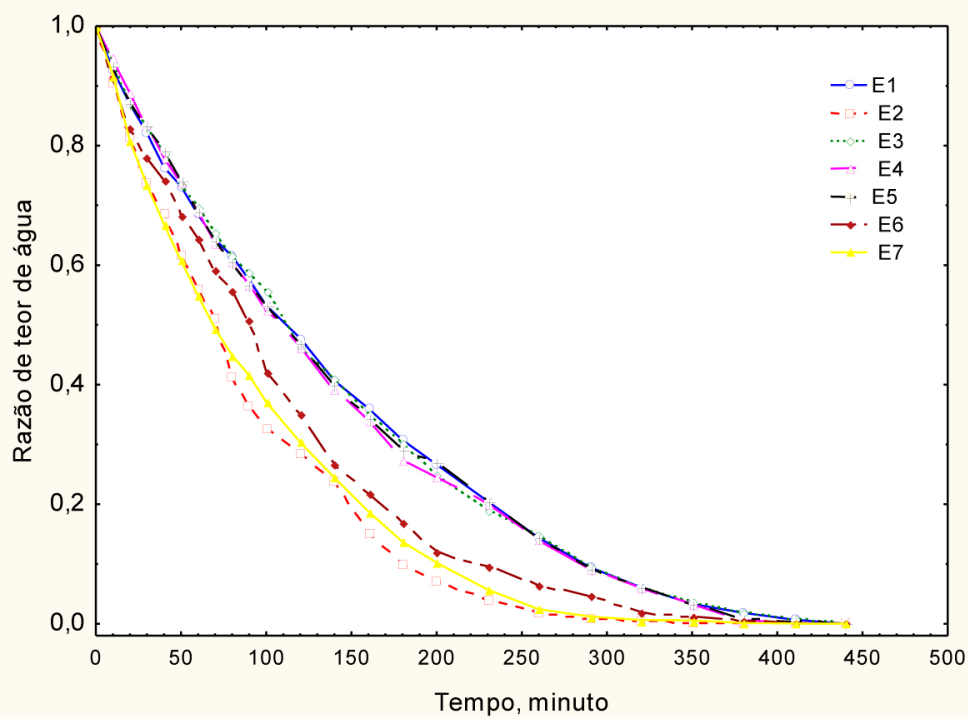

Figura 1 - Curvas da razão de teor de água (RU) em função do tempo para as secagens da matriz experimental. $\mathrm{E} 1=50^{\circ} \mathrm{C}$ e $2 \mathrm{~mm} ; E 2=70^{\circ} \mathrm{c}$ e $2 \mathrm{~mm} ; \mathrm{E3}=50^{\circ} \mathrm{C}$ e $4 \mathrm{~mm} ; \mathrm{E4}=70^{\circ} \mathrm{C}$ e $4 \mathrm{~mm} ; \mathrm{E5}=$ $60^{\circ} \mathrm{c}$ e $3 \mathrm{~mm} ; \mathrm{E} 6=60^{\circ} \mathrm{c}$ e $3 \mathrm{~mm} ; \mathrm{E7}=60^{\circ} \mathrm{c}$ e $3 \mathrm{~mm}$.

A nalisando as curvas de razão de teor de água, demonstrada na Figura 1, verifica-se que o aumento da temperatura favorece o processo de transferência de energia na forma calor para as amostras, consequentemente diminuindo o tempo necessário para a fruta atingir o equilíbrio, o mesmo comportamento foi observado por Doymaz (2005), Kaleemullah e Kailappan (2006), e Wang et al. (2007) e Santos et al. (2010).

Além disso, o processo de secagem ocorre na ausência do período da taxa constante de secagem, o que sugere o processo de difusão de umidade, do interior do produto para a superfície do mesmo, como o mecanismo físico predominante ao longo do processo. Concordantes com essa observação encontram-se os estudos realizados por Silva et al. (2009), para a secagem de banana maçã.

Conforme os resultados (Figura 1) verifica-se que o incremento na espessura apresenta efeito contrário na taxa de secagem, quando comparado com o aumento da temperatura, ou seja, a 
taxa de secagem diminui com o aumento da espessura, efeito corroborando com os resultados de Silva et al. (2009), estudando a secagem da banana maça em um secador de leito fixo.

Nas Tabelas 2 e 3, encontram-se os coeficientes das equações dos modelos da aproximação da difusão e Midilli, obtidos por regressão não linear, estimados pelo Método de Quase - Newton, utilizando o programa STATISTICA 5.0.

Nas Tabelas 2 a 3 são apresentados os valores dos coeficientes de determinação $\left(R^{2}\right.$, em $\%$ e os desvios quadráticos médios (DQM, em decimal) para os modelos analisados (modelos da aproximação da difusão e Midilli) para as secagens da matriz experimental.

Tabela 2. Parâmetros do modelo da aproximação da difusão obtidos através dos dados experimentais

\begin{tabular}{ccccccccc}
\hline Ensaio & $T\left({ }^{\circ} \mathrm{C}\right)$ & $\begin{array}{c}\text { Espessura } \\
(\mathrm{mm})\end{array}$ & $A$ & $b$ & $\begin{array}{c}k \\
\left(\mathrm{~min}^{-1}\right)\end{array}$ & $R$ & $R^{2}$ & $D Q M$ \\
1 & 50 & 2 & 0,9817 & 0,5189 & 0,0026 & 0,9991 & 0,9982 & 0,0023 \\
2 & 70 & 2 & 0,9781 & 0,6491 & 0,0308 & 0,9989 & 0,9979 & 0,0024 \\
3 & 50 & 4 & 0,9813 & 0,5423 & 0,0254 & 0,9993 & 0,9987 & 0,0021 \\
4 & 70 & 4 & 0,9836 & 0,6033 & 0,0223 & 0,9990 & 0,9981 & 0,0023 \\
5 & 60 & 3 & 0,9829 & 0,5672 & 0,0236 & 0,9981 & 0,9963 & 0,0032 \\
6 & 60 & 3 & 0,9725 & 0,5072 & 0,0371 & 0,9983 & 0,9967 & 0,0029 \\
7 & 60 & 3 & 0,9880 & 0,6106 & 0,0296 & 0,9993 & 0,9986 & 0,0019 \\
\hline
\end{tabular}

Tabela 3 - Parâmetros da Equação de Midilli e Kucuk obtidos através dos dados experimentais

\begin{tabular}{cccccccccc}
\hline Ensaio & $T\left({ }^{\circ} \mathrm{C}\right)$ & $\begin{array}{c}\text { Espessura } \\
(\mathrm{mm})\end{array}$ & $a$ & $b$ & $\begin{array}{c}k \\
\left(\mathrm{~min}^{-1}\right)\end{array}$ & $n$ & $R$ & $R^{2}$ & $D Q M$ \\
1 & 50 & 2 & 0,9989 & $-0,0002$ & 0,0048 & 1,0371 & 0,9995 & 0,9989 & 0,0017 \\
2 & 70 & 2 & 0,9831 & $-0,00003$ & 0,0051 & 1,1567 & 0,9989 & 0,9978 & 0,0026 \\
3 & 50 & 4 & 0,9842 & $-0,0001$ & 0,0035 & 1,1072 & 0,9995 & 0,9991 & 0,0016 \\
4 & 70 & 4 & 0,9971 & $-0,0001$ & 0,0044 & 1,0736 & 0,9997 & 0,9995 & 0,0012 \\
5 & 60 & 3 & 0,9989 & $-0,0002$ & 0,0048 & 1,0371 & 0,9995 & 0,9989 & 0,0017 \\
6 & 60 & 3 & 0,9831 & $-0,00003$ & 0,0051 & 1,1567 & 0,9989 & 0,9978 & 0,0026 \\
7 & 60 & 3 & 0,9842 & $-0,0001$ & 0,0035 & 1,1072 & 0,9995 & 0,9991 & 0,0016 \\
\hline
\end{tabular}

Conforme pode ser observado nas Tabelas 2 e 3, verifica-se que os modelos da aproximação da difusão e Midilli, apresentam ajustes com elevados coeficiente de determinação 
$\left(R^{2}\right)$ superiores a 99\% e baixos valores de desvios de quadráticos médios (DQM, em decimal) inferiores a 0,0032. Semelhantemente, Santos et al. (2010), ao estudar a influência de diferentes pré-tratamentos na cinética de secagem de banana da variedade Terra, o modelo de Midilli e Kucuk foi o que melhor se ajustou aos dados observados. Menges e Ertekin (2006) ao analisarem a cinética de secagem de maçãs douradas verificam que o modelo de Midilli e Kucuk ajustou-se com elevados valores de coeficiente de determinação. Com os modelos aplicados de A proximação da difusão, Corrêa et al. (2010) e o de Midilli et al. (2002), Sousa et al. (2011), obtiveram os maiores valores de $R^{2}$ e menores valores de DQM, ao ajustarem estes modelos à curva de secagem de polpa de Oiti nas temperaturas de 50,60 e $70^{\circ} \mathrm{C}$ em estufa com circulação forçada de ar. Por outro lado, Silva et al. (2009) ao estudar a secagem em camada fina da maçã em secador de leito fixo, os modelos que melhor representaram o processo de secagem foi o de Henderson e Pabis e o Exponencial 2 termos. Já Borges et al.(2010) ao estudar a secagem de banana prata d'água por convecção em um mini secador de bandeja, o modelo que melhor representou foi o exponencial. No estudo de Alexandre et al.(2013) a cinética de secagem do resíduo de abacaxi enriquecido em leito e estático ajustaram aos dados experimentais os modelos de Page, Henderson \& Pabis e Lewis.

\section{CONCLUSÕES}

As equações de Midilli et al. (2002) e aproximação da difusão representaram satisfatoriamente os dados experimentais para a descrição da cinética de secagem da farinha de banana verde com coeficientes de determinação superiores a 99\%. O tempo de secagem reduziu de forma mais rápida com o aumento da temperatura do ar de secagem.

\section{REFER $\hat{E} N C I A S$}

ALEXANDRE, H.V.; SILVA, F.L.H.; GOMES, J.P.G.; SILVA, O.S.; CARVALHO, J.P.D.; LIMA, E.E. Cinética de secagem do resíduo de abacaxi enriquecido. Revist. Br. de Eng. Agríc. e Amb. v.17, n.6, p.640-646, 2013.

BORGES, S.V.; MANCINI, M.C.;CORRÊA,J.L.G.;LEITE, J. Secagem de bananas prata e d'água por convecção forçada. Ciênc. Tec. Alimentos, Campinas, jul.-set. 2010.

CAMPOS, R.P; VALENTE, J.P; PEREIRA, W. E. Conservação pós-colheita de banana cv. Revis. Bras. de Frutic., v. 25, n.1,p. 172-174, abr. 2003.

CORRÊA, P. C.; Oliveira, G. H. H.; Botelho, F. M.; Goneli, A. L. D.; Carvalho, F. M. Modelagem matemática e determinação das propriedades termodinâmicas do café (Coffea arábica L.) durante o processo de secagem. Revist Cer, v.57, p.595-601, 2010. 
DOY MAZ, I. Drying behaviour of green beans. Journal of Food Engineering, v. 69, n. 2, p.161$165,2005$.

ERTEKIN, C., \& Y ALDIZ, O. Drying of eggplant and selection of a suitable thin layer drying model. Journal of Food Engineering, p.63, 2004.

IBGE. Levantamento sistemático da produção agrícola. Rio de Janeiro v.25 n.02 p.1-84 fev. 2014.

INSTITUTO ADOLFO LUTZ. Normas analiticas, métodos químicos e físicos para análise de alimentos. São Paulo, 533 p. 1985.

KALEEMULLAH S.; KAILAPPAN R. Modelling of thin-layer drying kinetics of red chillies, Journal of Food Engineering, v. 76, n. 4, p. 531-537, 2006.

LI, M.; SLAUGHTER, D.C.; THOMPSON, J.S . Optical chlorophyll sensing system for banana ripening. Postharvest Biology and Technology, 12, 1997.

MENGES, H. O.; ERTEKIN, C. Mathematical modeling of thin layer drying of Golden apples. Journal of Food Engineering, v. 77, n. 1, p. 119-125, 2006.

MIDILLI, A.; KUCUK, H.; YAPAR, Z. A. New model for single-layer drying. Drying Technology, v.20, p. 1503-1513, 2002.

PONTES, S. F. O; CARNEIRO, J. C. S; BONOMO, P; CHAVES, M. A. Processamento e qualidade de banana da terra (musa sapientum) desidratada. Dissertação (Mestrado em Engenharia de processos de alimentos), Universidade Estadual do Sudoeste da Bahia, 86 p. 2009.

SANTOS, P.; SILVA, F.S.; PORTO, A.G. SILVA, F.T.C.; FURTADO, G.F. Influência de prétratamentos na cinética de secagem em diferentes temperaturas de banana da variedade terra (musa sapientum, linneo). Rev. Bra. de Tec. Agro. v. 04, n. 02: p. 218-234, 2010.

SILVA, A.S.; Melo, K.S.; ALVES,N.M.C.; FERNANDES;T.K. S.T.;FARIAS, P.A.F. Cinética de secagem em camada fina da banana maçã em secador de leito fixo. Rev. Bra. de Prod. Agro., Campina Grande, v.11, n.2, p.129-136, 2009.

SOUSA, F.C.; SOUSA, E.P.; SILVA,; MARTINS, L.M.M.; GOMES, J.J.A; ROCHA, A.T.R. Modelagem matemática para descrição da cinética de secagem de polpa de oiti. Rev. Ed. Agríc. Sup. v.26, n.2, p.108-112, 2011.

WANG, Z.; SUN, J.; LIAO, X.; CHEN, F.; ZHAO, G.; WU, J.; HU, X. Mathematical modeling on hot air drying of thin layer apple pomace. Food Research International, v. 40, n. 01, p. 39-46, 2007. 